\title{
Brick-and-Mortar to Click- and-Slide: An analytical study.
}

\author{
${ }^{1}$ T.R.Ramakrishnan, ${ }^{2}$ Ashwini K Deepak, ${ }^{3}$ Prof.Dr.K.Puttaraju \\ ${ }^{I}$ Faculty with the Jain Group of Institutions and a Research Scholar with Bangalore University \\ ${ }^{2}$ Faculty with the Jain Group of Institutions, Bangalore. \\ ${ }^{3}$ Professor in Communication and Director of Academic Staff College, Bangalore University.
}

\begin{abstract}
The business community globally has embraced technological innovations and revolutionized communication capabilities among people which has enhanced globalization and prosperity. This paper makes an attempt to understand the nature of this new innovative technology enabled services: how it's used, what are the quality control models and what is the experience of the bank and its customers on using Information and Communication Technology(ICT) for transactions, for good and for ill with the largest bank in India namely the State Bank of India. The study engages a qualitative research method and follows an exploratory research approach. Content analysis and discussions were conducted with an interview schedule among key managers at State Bank of India. The level of measurement applied in data analysis is Strengths, weaknesses, Opportunities and Threats(SWOT). The paper will identify the framework for technology management for the financial services system of the Bank. The study makes an attempt to evaluate the use of technological tools and activities to maintain the new type of services to the bank's customers.
\end{abstract}

Keywords : Banking services, Customer, ICT tools.

\section{Introduction}

TECHNOLOGICAL innovation has proved to be a dynamic factor in business process re-engineering especially in the banking sector. Innovation is a constant process that needs to match with changing environment. The invention of microprocessors, fiber optics combined with lasers and satellites have revolutionized communication capabilities among people across multi-national cultures and facilitated major advances in finance that greatly enhanced our ability to direct scarce savings into productive capital investments, which is a critical enabler of rapidly expanding globalization and prosperity[1]. With the increasing development in technology, the studies in the field of e-commerce becomes more and more attractive[2]. It is indicated that the winners in "clicks and order" retailing, like their predecessors in "brick and mortar" retailing, will be those who know how to take care of their customers better than competitors and provide better solutions to consumers than were available in the past [3]. These reveal that good customer relationships would lead to gain customer loyalty using technology.

The unique characteristics of services described in a study are intangibility, inseparability, heterogeneity, and perishability[4]. With the growth of Information and Communication Technology(ICT), the increased use of Internet has a big impact on these four characteristics. E-services have three special properties, quantization, the ability to search information, and the ability to automate[5]. Hence, the internet accessibility through world wide web tops the pre-requisite for conducting quality e-commerce services.

The internet affects services quality in banking sector. It is measured by the five important factors of reliability, responsiveness, security, communication and access in a study and identified that access as the most important dimension in service quality[6]. The quality factors that are highly important to consumers are efficiency and speed[7]. Another study attempted to establish the relationship between technology and service quality in the banking industry in Kenya and identified secure services as the most important dimension, followed by convenient location of Automated Teller Machine(ATM), efficiency, ability to set up accounts so that the customer can perform transactions immediately, accuracy of records, user friendly, ease of use, complaint satisfaction, accurate transactions and operation in 24 hours[8].

In India technology has become the differentiator and driver of the Indian banking system. According to the RBI report, the PSU banks collectively spent Rs.22.052 billion on ICT in the last decade technically between September, 1999 and March, 2010. State Bank of India has spent Rs.0.429 billion in the financial year 2010 which is the highest amongst all PSU banks. State Bank of India spent Rs.512 crores in financial year(FY)2011 and Rs.0.537 billion in FY 2010. State Bank of India has the highest number of ATMs with 8,548 in 2009 and 16,204 machines in 2010 among all the banks in India. Thus SBI customers are increasingly transacting using technology in India.

Further, the Financial inclusion was a challenge for Public Sector Units(PSU) and using the business correspondent model. They were able to create about 20 million personal bank accounts. The mere opening of 
account is not enough to measure financial inclusion but need to check with bank customers as how many services offered by the bank has been used regularly.

The share of electronic transactions to total transactions increased from $32.8 \%$ to $40 \%$ volume-wise and from $83.9 \%$ to $89 \%$ value-wise during the Financial year 2010. To encourage the electronic transactions, the waiver of processing charges for Real Time Gross Settlement (RTGS), National Electronic Funds Transfer (NEFT), National Electronic Clearing Service (NECS) and Electronic Clearing Service (ECS) was further extended up to March 31, 2011. RBI has also permitted ICL, NSCCL to settle funds of OTC trades of the corporate bond transactions in RTGS. RBI had asked banks to draw up a roadmap to provide banking services through a banking outlet in every village having a population of over 2,000 by March, 2011, either through a brick and mortar branch or through various forms of ICT based models. Investment in technology development and maintenance is an important policy for State Bank of India(SBI)[9].

Citibank highlighted on the relationship perspective in a study, which is about speed, convenience, customer service, keeping things simple, and advice about wealth management - it is a complete package according to Mr.Anand Selvakesari, Head-Consumer Banking of Citibank,. If some fees are waived, customers tend to value that and be extremely loyal. Mr Anand notes that at present India has the largest remittance flows in the world and the personal consumption as per market estimates stands at Rs.45 lakh crore and is expected to touch Rs.85 lakh crore by 2015[10].

There are policies in Indian Banking system that need constant amendments to boost e-commerce. The Finance Ministry has issued a notification allowing Banks to advertise either their own products and services or those of broking firms, mutual funds, insurance companies and pension funds on the ATM screen[11].

As per National Payment Corporation of India's data, the 77 banks that are connected to its National Financial Switch collectively had a network of 91,324 ATMs. The number of cash withdrawals and the number of balance enquiries accounted for 74 per cent and 24 per cent respectively of the total volume of 0.16 billion transactions in February 2012. Further, the Reserve bank of India may cut interest rate by about 0.25 per cent and release more liquidity to stimulate economic growth in its annual credit policy[12], which will increase the number of transactions. Thus we notice the trend is towards integration of technology enabled banking tools.

Though the banks driven by National Bank for Agriculture and Rural Development(NABARD) and Regional Rural Banks(RRB)'s, are not too attractive for creating new accounts by investing in ICT infrastructure, many banks have invested in ICT infrastructure for financial inclusion. SBI has its own financial switch to network with all its branches. The systems are geared to take low-value high-volume transactions from 500 to 1500 transactions per second. The technologies deployed for financial inclusion are: Biometric smart card, Handheld biometric Point of Sale(POS) device for authentication and transaction, General Packet Radio Service(GPRS)enabled mobile phones, Core banking solution. The POS used by banks include voice guidance in the local languages to facilitate the semi-literate and the functionally literate villagers to understand transactions carried out by them. These facilities have increased banking transactions. The key issues in automation today are frauds, costs and resistance to change by employees[13].

In order to uphold the $9 \%$ economic growth during $12^{\text {th }}$ five year plan(2012-2017), India's gross domestic savings to Gross Domestic Production(GDP) has to touch a level of 38\%[14]. Banks need to make use of this business opportunity. Therefore, a study on the awareness, use and strengths and weaknesses of ICT enabled banking functions is a felt need. This paper looks at the Alternative channel services from the traditional services of State Bank of India, Bangalore and tries to identify if there is awareness of ICT tools and use of technology by customers to SBI.

\section{Problem Discussion}

From the foregoing it is clear that in order to assess an e-commerce project, it is mandatory to identify the customer's awareness and experience on using technology for financial transactions. Banking being a service industry needs to spearhead in its quality services towards satisfying customers. Delivering superior services has become one of the most important ways to gain superior profitability. Further, maintaining effective customer service helps to build and maintain customers relationship that is the key success in e-commerce[15]. Technology enabled banking transactions involve high end communication between two using computers, customers and banks information system stored in a server.

Hence, the research problem is formulated as follows: To understand the various ICT tools used in Alternative channels services in Banking especially with SBI and it's use among customers. Further, due to the growth in use of varied ICT functions and tools for banking transactions, the process of technology management is conceptualized for argument.

\section{Objectives}

The objective of the paper is to understand the nature of the new innovative technology enabled services: how it is used, what are the quality control models and what is the experience of the bank and its 
customers on using ICT for transactions, for good and for ill with the largest bank in India namely the State Bank of India.

\section{Methodology}

There are six sources of evidence which are available for collecting qualitative data: documentation, archival records, interviews, direct observations, participant observations and physical artifacts[16]. The two common sources selected for this study were documentation and interview. A face-to-face interview was conducted in this study by using open ended and close ended questions to managers and customers of the State Bank of India.

\section{Sample Selection}

The banking requirements of micro, small and medium enterprises(MSME) sector has made SBI to leverage technology to the SME customers, who are one among the strong drivers to sustain the economy. Nonprobability sampling were selected using Judgment sampling method. In this paper the sample selected was the customers of SBI who had assembled for the Times of India SBI SME Utsav to address the Small and Medium Enterprises (SMEs) issues and educate SME customers on SBI products. These respondents were interviewed using a closed ended questionnaire. Further, discussions were generated with Mrs. Neerja Nigam, Deputy General Manager, Alternative Channels and Payments and Mr. Ravikant Kurtagoti Assistant General Manager, Information Technology Services, State Bank of India, Bangalore. Both have over 20 years of work experience in the Bank.

\section{Data Presentation And Analysis}

A survey questionnaire was administered to the customers and the data was analysed subject to statistical analysis.

Qualitative data analysis is concerning of three flows of activity: data reduction, data display, and conclusion drawing or verification. They have suggested within case analysis and across-case analysis[17]. This study further conducted within case analysis. The empirical data has been presented and organized based on the subunits of analysis namely: Strengths, Weakness, Opportunities and Threats of SBI's ICT enabled Alternative channel Services.

The general idea of SWOT analysis is that a firm's strategy must be build on its strengths, try to remedy the weaknesses or work around them, take advantage of the opportunities presented by the environment and protect the organization from the threats. SWOT is simple and does not sacrifice the analytical rigour[18]

\section{Findings}

The various entrepreneurs from small and medium enterprises were interviewed during the SBI SME Utsav at the SBI office, St.Marks Road, Bangalore and the data was gathered from thirty two respondents and tabulated as given in Table 1 .

\section{TABLE 1: AWARENESS AND EXPERIENCE OF TECHNOLOGY ENABLED SERVICES OFFERED TO} THE SME BY STATE BANK OF INDIA.

\begin{tabular}{|c|l|c|c|c|c|c|}
\hline Sl.no & Technology enabled Services & \multicolumn{2}{|l|}{ Awarenss } & \multicolumn{2}{l|}{ Had Experience } \\
\hline & & Yes & No & Always & Sometimes & Never \\
\hline 1 & Real Time Gross Settlement (RTGS) & 18 & 14 & 2 & 7 & 23 \\
\hline 2 & $\begin{array}{l}\text { National Electronic Fund Transfer } \\
\text { (NEFT) }\end{array}$ & 22 & 10 & 3 & 7 & 22 \\
\hline 3 & $\begin{array}{l}\text { Society for Worldwide Internet Financial } \\
\text { Telecom (SWIFT) }\end{array}$ & 16 & 16 & 2 & 6 & 24 \\
\hline 4 & Www.statebankofindia.com & 24 & 8 & 4 & 10 & 18 \\
\hline 5 & Mobile phone banking & 20 & 12 & 1 & 7 & 24 \\
\hline 6 & Internet banking & 25 & 7 & 4 & 10 & 18 \\
\hline 7 & E-mail supported response on grievances & 18 & 14 & 0 & 9 & 23 \\
\hline 8 & ATMs & 24 & 8 & 9 & 7 & 16 \\
\hline 9 & Core banking facility & 23 & 9 & 8 & 5 & 19 \\
\hline 10 & Credit and Debit cards & 25 & 7 & 9 & 5 & 18 \\
\hline 11 & Gift cards & 13 & 19 & 1 & 4 & 27 \\
\hline 12 & Travelers' cards & 16 & 16 & 1 & 5 & 26 \\
\hline 13 & Point of Sale (POS) & 9 & 23 & 1 & 1 & 30 \\
\hline 14 & Cash Transfer Machines(CTM) & 1 & 31 & 1 & 0 & 31 \\
\hline 15 & Call center - 1800-11-22-11 & 12 & 20 & 0 & 5 & 27 \\
\hline 16 & E-VFS & 0 & 32 & 0 & 0 & 32 \\
\hline
\end{tabular}


Brick-and-Mortar to Click- and-Slide: An analytical study.

\begin{tabular}{l|l|l|l|l|l|l|}
17 & E-DFS & 3 & 29 & 0 & 0 & 32 \\
\hline
\end{tabular}

From the above Table 1 it is observed that over $50 \%$ of the respondents did not have experience in any of the technology enabled services. However, over $60 \%$ of the respondents were aware about the services. $78 \%$ of the respondents were aware about the Internet banking but only $44 \%$ had used. The figure is the same for credit and debit cards. $75 \%$ were aware about the website of State Bank of India but $44 \%$ had visited the website. Again $75 \%$ were aware about the SBI ATM but only $50 \%$ used them. About $72 \%$ were aware about Core Banking Services and $41 \%$ used this facility. National Electronic Fund Transfer (NEFT) was known to $69 \%$ and $31 \%$ used this service. Though the trend setting concept is Mobile banking, 63\% were aware and 25\% used it. The feature of Real Time Gross Settlement (RTGS) was known to 56\% of the SMEs but $28 \%$ actually used RTGS. Only $56 \%$ were aware that grievances could be sent to managers by email but $28 \%$ irregularly used this mode of communication. Society for Worldwide Internet Financial Telecom (SWIFT) services was used by $25 \%$ but $50 \%$ were aware about the services. Again 50\% were aware about travelers cards but 19\% had experience using them. $41 \%$ were aware about gift cards and $16 \%$ used atleast once. $38 \%$ were aware about the call center number and $16 \%$ had called the atleast once. $28 \%$ knew about POS services but only $3 \%$ used it. And hardly anyone was aware about Electronic Dealer Finance System(E-DFS), Cash Transfer Machines(CTMs), Electronic Vendor Finance System(E-VFS) and neither have they used these services.

By using Non-parametric test, the data in table 1 is being represented by graph as given below.

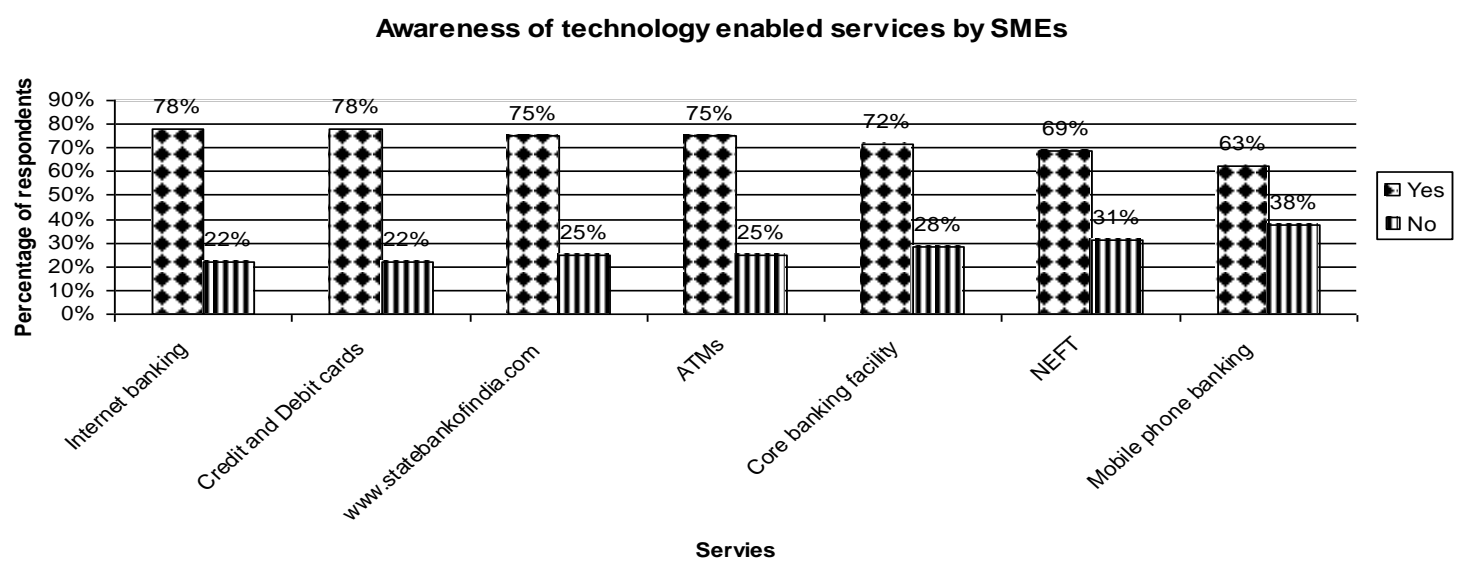

Figure 1. Awareness of ICT services of SBI by SMEs

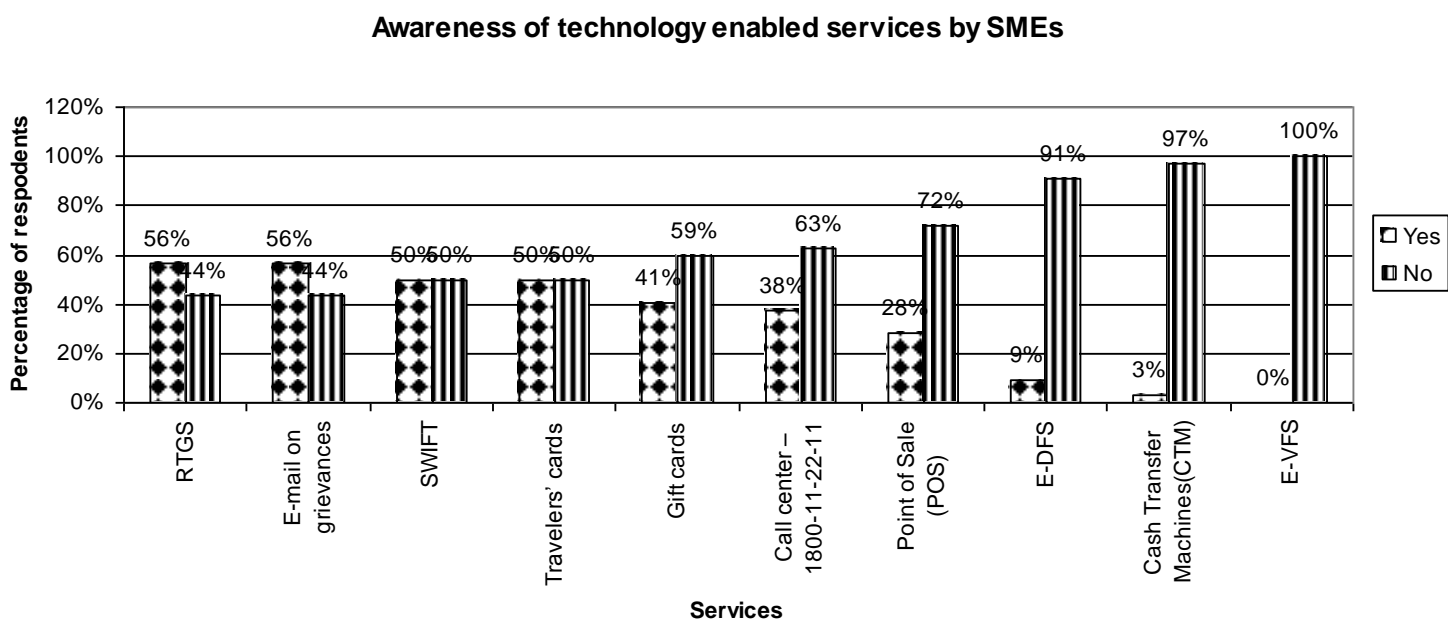

Figure 2. Awareness of ICT services of SBI by SMEs

Upon intervening with the respondents about their awareness about electronic banking services, it was revealed that more customers are aware about ATM banking, Debit or credit card transaction, internet banking, Core banking facilities and mobile banking than RTGS, NEFT, SWIFT, email support, gift cards, travelers cards, POS, CTMs, Call center, E-VFS and E-DFS. This implies that SME banking customers are more familiar with ATM and use of debit and credit cards and CBS put together compared to other services shown in Table 1. 
Experience in using ICT services by SMEs

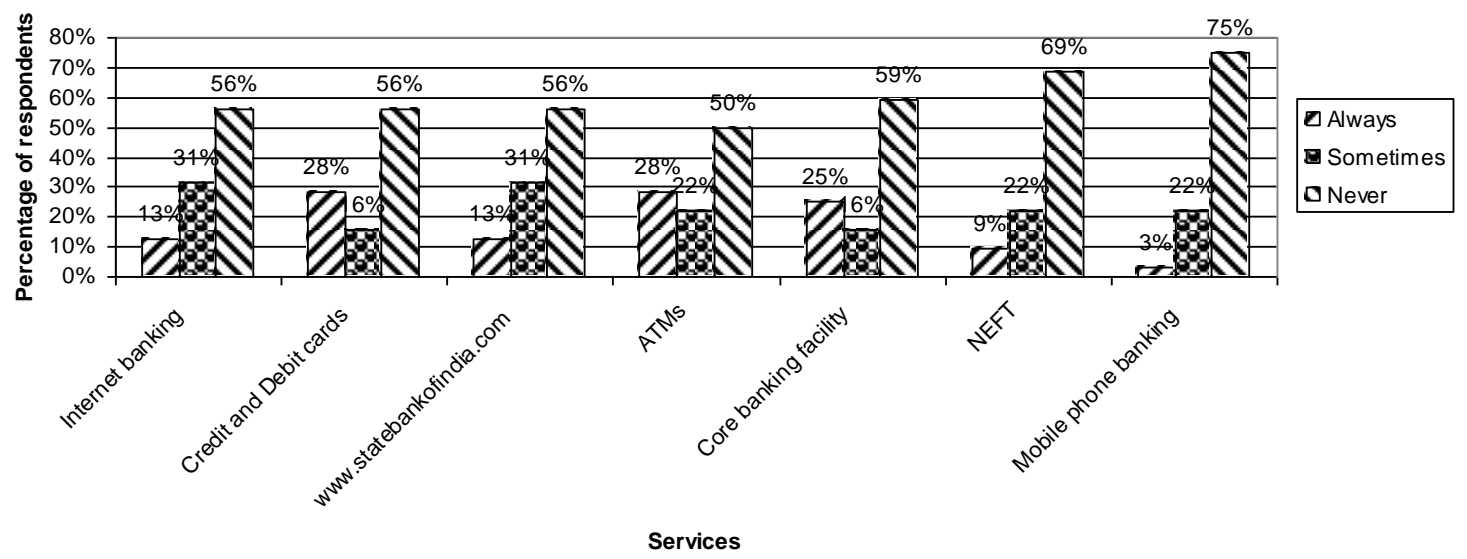

Figure 3. Experience of using ICT services by SMEs

Experience in using ICT services by SME2

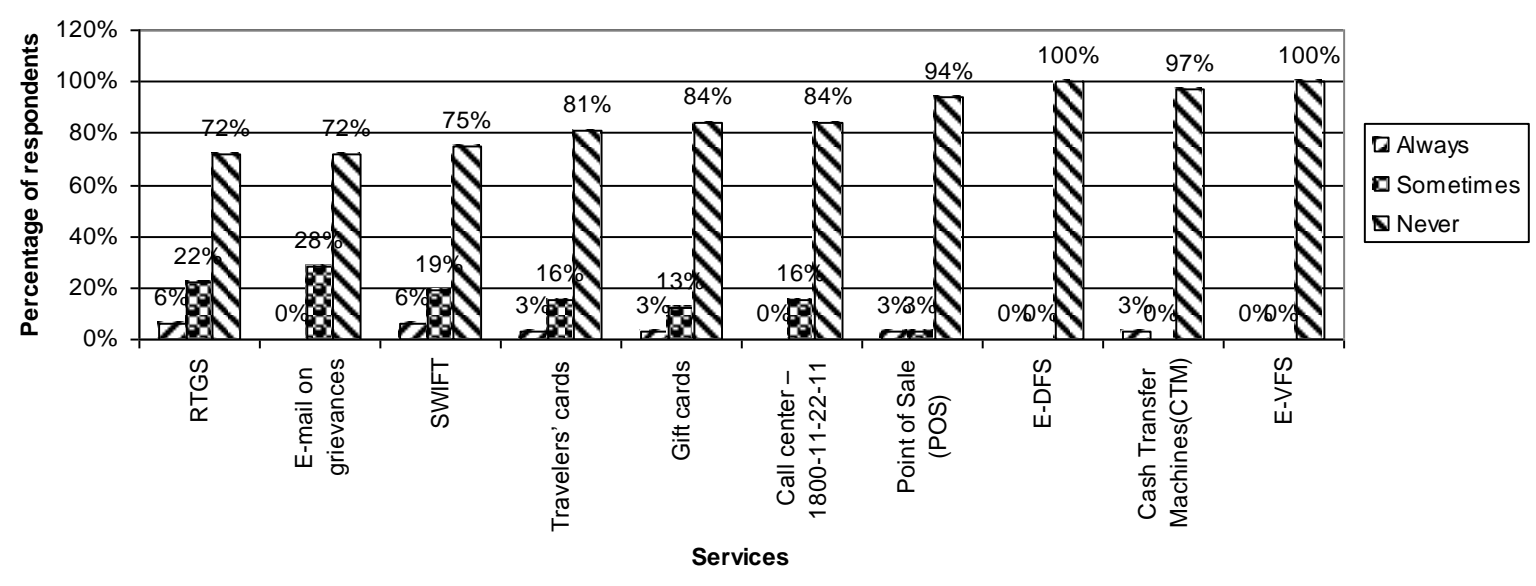

Figure 4. Experience of using ICT services by SMEs

When the respondents were questioned about their usage to electronic banking services, it was shown that more customers have adapted to ATM banking than mobile and internet banking. This implies that the banking customers are more familiar with the ATM technology as compared to both internet and mobile banking. Mrs. Neerja Nigam, Deputy General Manager, Alternative Channels and Payments were interviewed on the Strengths, Weakness, Threats and Opportunities of the use of Alternative Channels both from the banks operations and customer's environment.

\section{A. Strengths}

It is clear from the analysis that SBI's ATM banking has taken over traditional personal banking transactions by over $46 \%$ of the total transactions in Bangalore. Due to it's enormous growth in transactions and new customer creation, the bank has its own financial switch center managed at the Global IT center, Bellapur, Mumbai. Karnataka alone has over 5 million customers using Alternative channels and is growing by the day. The connection is up 24/7 365 days using Very Small Aperture Terminal(VSAT) and Reliance Code division multiple access(CDMA) for remote areas. The bank's use of cryptography technology enables high level of password protection and validation for every screen based clicks or slides. Value added facilities in ATMs like payment of bills, taxes and donations, card to card transfers of the same bank are becoming popular. The introduction of Bunch Note Acceptor(BNA) and Self Service Kiosk(SSK) to check transactions and print on pass books would further enhance customer expectations and reduce rush in banks branches. 


\section{B. Weakness}

One of the weakness of the SBI alternative channels services is that it cannot maintain accounts with zero balance and minimum balance of Rs.100. It is also difficult to network with rural areas where the telecommunication towers are located far away from the branch or Kiosks which fail to fulfill the financial inclusion by the bank. These branches need staffs who can speak in the local language and who are qualified to work with SBI.

\section{Threats}

There is only one threat to the technology enabled alternative channel services and that is Cyber crime.

\section{Opportunities}

With the growth in transactions over online banking and ATM banking services beyond the Core banking solutions, it is necessary to integrate ATM services along with Bunch Note Acceptor and Self Service Kiosk into one application in SBI ATMs. This way there could be higher value in transactions and gain profits by service charges. With the growth of mobile communication in India, SBI has greater opportunity to expand in mobile banking, ATM services and Online banking in rural areas. The present system in Bangalore One and Karnataka One could handle many of the services provided by the bank to its customers beyond being visible in Post Offices.

It was learnt from the overseas bank manager that their office uses (Export Import)EXIM software for all operations of the export and import transactions. Core Banking Services and Mercury are the other software packages used for banking operations which are linked to the Alternative channel services.

Mrs. Neerja states that the cost to bank using manual transactions is Rs.40/- per transaction but it is safe. It costs Rs.20/- per ATM transaction and is also safe. Internet transactions costs Rs.12/- and is safe but mobile transactions cost Rs.1/- per transactions but at present the authorities feel it is unsafe and hence the transactions are limited to a value of Rs.2,000/- and account enquiry on the last 5 transactions can be gathered using mobile phone.

\section{Summary And Conclusion}

From the findings of the interactions among the sample indicates that there is high awareness on over $50 \%$ of the ICT enabled banking services of State Bank of India. Due to the lack of training and opportunity to utilize the technology based services, many of the entrepreneurs from Small and Medium Enterprises of Bangalore resist the usage. Nevertheless, the growth of technology has been seen that use of ICT services as the cutting edge factor for competitive advantage. Hence, this research was carried out in SBI, the largest banker in India. It was established that there is a direct relationship between awareness and experience in use of ICT services in SBI products. The use of technology also enhances the freedom and service features offered to customers. But the level of utilization differs with service experience and education of the customer. This was possible through use of percentages and graphical representations. As the test variables were controlled by fixed and continuous scale, further statistical analysis could not be conducted in this study. The growth in transactions in SBI financial switch indicate that the expert in technology banking customers always look ahead for innovations in technology with integration of tools compared to novice users. This situation needs to be analyzed for banks to take a strategic decision whether to go ahead in IT investment for innovation or not.

It is advised that the customers could have value addition in the cool ambience in ATM banking especially with music and advertisements while transacting inside the kiosk. Alerts can also be mentioned over the audio system about risks and convenience in using ATMs.

Mr.Anand Selvakesari, Head-Consumer Banking in Citibank feel speed, convenience, customer service, and keeping things simple are some key factors for good customer relationship in technology banking. Thus, more customers should be trained in Online and mobile banking apart from visitors to the branch or ATMs. Commerce and management students could be assigned with internships to train customers on site to use their own mobile phones and the students laptops to showcase and train walk in customers. Further, they could collect a feedback from the customers on their expectations, needs and wants from SBI Information Technology Services and Alternative Channels and Payment services.

The study strongly recommends that the Ministry of Human Resource Development(MHRD) and Ministry of Commerce, Government of India pitch in to meet the account maintenance charges of the banks for the people maintaining a zero or less than Rs.500/- balance in savings bank customers accounts. This will enhance the financial inclusion of the citizens of India.

The paper has a limitation on gathering official data from Mr. Ravikant Kurtagoti Assistant General Manager, Information Technology Services, State Bank of India in Bangalore in order to identify the framework for technology management for the financial services system of the Bank. Hence, it could not assess the efficacy of the technological gadgets and activities to maintain the new type of services to the bank customers. It is 
hypothesized that with the new tools on mobile applications and web applications being introduced in the market in short intervals, the changing consumer needs would have to be met for furthering transactions over ICT tools. On identifying the trend on usage of technology enabled tools in India, the researcher recommends that a study should be carried out to identify the trust on ICT banking services delivery using Alternative channel services. Further the quality control framework need to be identified to find the role of customers in the strategic decision making of re-engineering of ICT enabled services in State Bank of India. To conclude cooperative banks in rural areas have begun to automate their operations which are a positive sign towards ICT enabled banking services for the last mile connect. This will change the entire nation's traditional banking system from Brick-and-Mortar to Click- and-Slide. It is a vision and to note that mobile banking would take over ATM banking and currency printing maybe eliminated for few denominations which maybe replaced by digital money resulting in savings to the Government of India and Reserve Bank of India.

\section{References}

[1] Alan Greenspan, The Age of Turbulence: Adventures in a New World: Adventures in a new world, New York:Penguin Group, 2007

[2] Wingand, R.T. and Kling, R., "Electronic Commerce: Definition, theory and context", in Information society, Vol. 13 Issue 1, January - March 1997,pp, 1-16.

[3] Blackwell, R.D, Miniard, P.W and Engel, J.F., Consumer Behaviour, ${ }^{\text {th }}$ Ed, Orlando Fl: Hardcourt College Publishers, 2001.

[4] Parasuraman, A Zeithamal, V.A, and Berry, L.L., "A conceptual model of service quality and its implications for future research", Journal of Marketing, Vol 49, 1985

[5] Hoffman, K.D, and Bateson, J.E.G , Essentials of Services Marketing: Concepts, strategies and cases, $2^{\text {nd }}$ ed, Harcourt College Publisher,2002.

[6] Chun Wang, Zheng Wang, "The Impact of Internet on service quality in Banking Sector", Lulea University of Technology, Department of Business Administration and Social Sciences, 2007

[7] Bateson, J. (1985), Perceived control and the service encounter, in Czepiel, J.A., The Service Encounter:Managing Employee/Customer Interaction in Service Businesses, Lexington, MA.: Lexington Books, 1985.

[8] Thomas Ogoro Ombati, Peterson Obara Magutu, Stephen Onserio Nyamwange Wingand, R.T. and Kling,R., "Electronic Commerce:Definition, theory and context", Information society, Vol.13 Issue 1, January-March 1997, pp,1-16.

[9] Dataquest : Focus : Indian Banking Gets Robust with Tech Updation , Available: http://dqindia.ciol.com/content/industrymarket/focus/2010/110123102.asp

[10] Priya Nair, "The potential for growth in retail banking is huge", Business Line, Bangalore: The Hindu, $16^{\text {th }}$ April 2012.

[11] Ram Kumar K, "Banks allowed to run ads on ATM screens", Business Line, Bangalore:The Hindu, $16^{\text {th }}$ April 2012.

[12] PTI, "RBI may cut CRR, repo by $0.25 \%$ in upcoming policy say bankers", Deccan Herald, Bangalore, $16^{\text {th }}$ April 2012.

[13] Ernst \&Young(2011), "Technology in Banking - Insight \& Available:http://www.ey.com/Publication/vwLUAssets/Technology_in_Banking_-

Insight_and_Foresight_IDRBT_EY_REPORT/\$FILE/Technology-in-Banking-Insight-and-Foresight-IDRBT-EY-REPORT.pdf

[14] Joanna Punjabi, "Banking in India-on the road to innovation", Forbes India Marquee, a special marketing supplement, Mumbai: Digital 18 Media Ltd., November 2012.

[15] Kotler,P(2003), "Marketing Management", International edition, NJ: Prentice Hall, 2003.

[16] Yin, R.K, "Case study research- Design and Methods, $2^{\text {nd }}$ edn, London: Sage publications, 1994

[17] Marshall, C., \& Rossman, G. B., Designing qualitative research. Thousand Oaks, CA: Sage Publications, Inc, 1999

[18] Gregory G. Dess, G.T. Lumpkin, Alan B. Eisner, "Strategic Management: Text and cases", NY: McGraw-Hill Irwin,2008 